$\frac{96}{2-12.90} \delta^{\top}$

\title{
Chemical Characterization of CTBN and its Epoxy Adduct
}

Kansas City Division

R. E. Smith

KCP-613-4222

Published January 1990

Topical Report

\section{DO NOT MICROFLL \\ COVER}

Prepared for the United States Department of Energy Under Contract Number DE-AC04-76-DP00613.

\section{Allied-Signal Aerospace Company}




\section{DISCLAIMER}

This report was prepared as an account of work sponsored by an agency of the United States Government. Neither the United States Government nor any agency Thereof, nor any of their employees, makes any warranty, express or implied, or assumes any legal liability or responsibility for the accuracy, completeness, or usefulness of any information, apparatus, product, or process disclosed, or represents that its use would not infringe privately owned rights. Reference herein to any specific commercial product, process, or service by trade name, trademark, manufacturer, or otherwise does not necessarily constitute or imply its endorsement, recommendation, or favoring by the United States Government or any agency thereof. The views and opinions of authors expressed herein do not necessarily state or reflect those of the United States Government or any agency thereof. 


\section{DISCLAIMER}

Portions of this document may be illegible in electronic image products. Images are produced from the best available original document. 


\section{The following pages are an exact representation of what is in the original document folder.}


This report was prepared as an account of work sponsored by an agency of the United States Government. Neither the United States Government nor any agency thereof, nor any of their employees, makes any warranty, express or implied, or assumes any legal liability or responsibility for the accuracy, completeness, or usefulness of any information, apparatus, product, or process disclosed, or represents that its use would not infringe privately owned rights. Reference herein to any specific commercial product, process, or service by trade name, trademark, manufacturer, or otherwise, does not necessarily constitute or imply its endorsement, recommendation, or favoring by the United States Government or any agency thereof. The views and opinions of authors expressed herein do not necessarily state or reflect those of the United States Government or any agency thereof.

Printed in the United States of America.

This report has been reproduced from the best available copy.

Available to DOE and DOE contractors from the Office of Scientific and Technical Information, P.O. Box 62, Oak Ridge, Tennessee 37831; prices available from (615) 576-8401, FTS 626-8401.

Available to the public from the National Technical Information Service, U. S. Department of Commerce, 5285 Port Royal Rd., Springfield, Virginia 22161.

Price Code: Printed Copy $\mathrm{A03}$ Microfiche A01 
$\mathrm{KCP}-613-4222$

Distribution Category UC-70I

CHEMICAL CHARACTERIZATION OF CTBN AND ITS EPOXY ADDUCT

$\mathrm{KCP}--613-4222$

DE90 006397

R. E. Smith

Published January 1990

Topical Report

R. E. Smith, Project Leader

Project Team:

E. N. Fuller

Technical Communications

Kansas City Division

\section{Allied-Signal Aerospace Company}


THIS PAGE

\section{WAS INTENTIONALLY \\ LEFT BLANK}


CHEMICAL CHARACTERIZATION OF CTBN AND ITS EPOXY ADDUCT

KCP-613-4222, Topical Report, Published January 1990

Prepared by R. E. Smith

This report describes the analysis of carboxyl-terminated butadiene (CTB), carboxyl-terminated butadiene/acrylonitrile (CTBN), and a CTBN adduct prepared by reaction with Epon 828 . Data from gel permeation chromatography, nuclear magnetic resonance spectroscopy, high performance liquid chromatography, and ion chromatography are presented and discussed. Quantitative methods based on carbon-13 and proton NMR for analyzing CTBN are described. Proton NMR was found to be useful in identifying lots. that have an abnormal amount of CTBN protons. One such lot exhibited a phase separation of a polybutadiene impurity.

Carbon-13 NMR was found to be capable of determining nitrile content directly. Carbon-13 NMR had a relative standard deviation of $8.3 \%$ and a proton NMR of $3.9 \%$. Proton NMR was found to be useful in identifying lots that have $5 \%$ more CTBN protons than other lots.

$S W: j \mathrm{db}$

DTR173/a

A prime contractor with the United States Department of Energy under Cunitract Number DE-AC04-76-DP00613
Kansas City Division P.O. Box 419159 Kansas City, Missouri 64141-6159 
CONTENTS

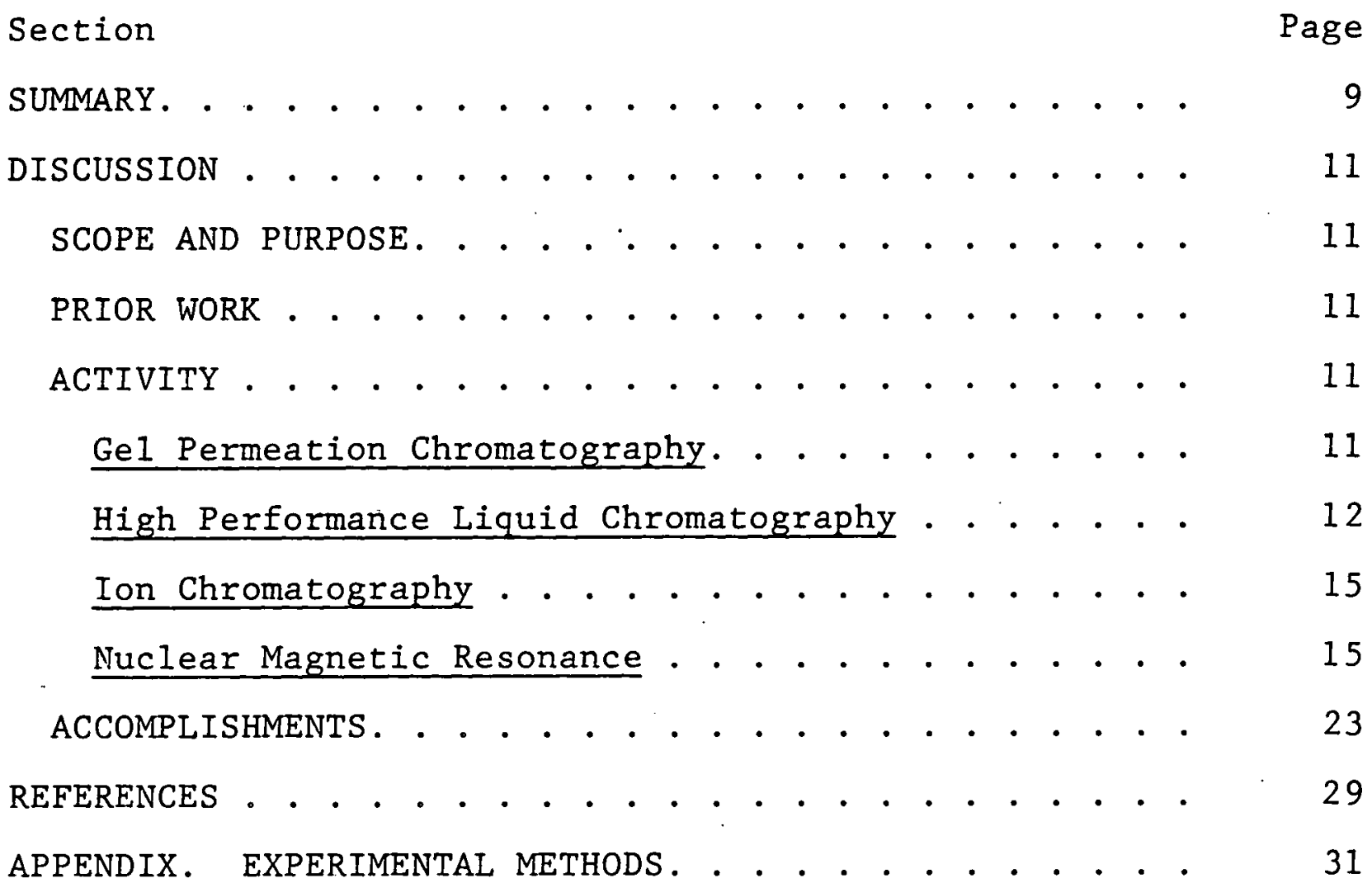




\section{ILLUSTRATIONS}

Figure

1

2

4

5

6

7

8

9

10

11

GPC of CTBN $1300 \times 8$

Page

GPC of Epon 828-CTBN Adduct. . . . . . . . . . 14

HPLC of CTB--Absorbance at $253 \mathrm{~nm}$. . . . . 16

HPLC of CTB--Absorbance at $220 \mathrm{~nm}$. . . . . . 17

HPLC of CTBN $1300 \times 8$. . . . . . . . . . 18

Proton NMR of CTBN $1300 \times 8$. . . . . . . . 20

Proton NMR of $\mathrm{CTB}$ in $\mathrm{CDCl}_{3}$. . . . . . . . . 21

Proton NMR of Epon 828-CTBN Adduct in $\mathrm{CDCl}_{3}$

13

4

6

7

8

0

Carbon-13 NMR of CTBN $1300 \times 8$ in $\mathrm{CDCl}_{3} \cdot$. . : 24

Carbon-13 NMR of CTB in $\mathrm{CDCl}_{3}$. . . . . . . . . 25

Carbon-13 NMR of Epon 828-CTBN Adduct in $\mathrm{CDCl}_{3} \cdot$. . . . . . . . . . . . . .

\section{TABLES}

Number

GPC Data on CTBN • • . . . . . • . . . •

Page

Ions in Epoxy and Adduct . . . . . . . . . .

Proton NMR Analysis Showing Hydrogen in Samples of CTBN/Epon 828 . . . . . . . . .

Carbon-13 NMR Analysis Showing Carbon in Samples of CTB and CTBN. . . . . . . . . 
SUMMARY

Methods have been developed for analyzing a carboxyl-terminated butadiene/acrylonitrile (CTBN), Hycar $1300 \mathrm{X} 8$, from

B. F. Goodrich, Akron, OH, and the CTBN-epoxy adduct, KCD 20102. For comparison, carboxyl-terminated butadiene (CTB), Hycar $2000 \mathrm{X162}$, from B. F. Goodrich was analyzed also. The molecular weight distribution was measured by gel permeation chromatography (GPC) using a Waters model 150C gel permeation chromatograph equipped with three microstyrogel columns in tandem, with 1000 , 500, and 100 angstrom pore size and refractive index detection. High performance liquid chromatography (HPLC) was performed on a Dionex model 4000 liquid chromatograph equipped with a HewlettPackard 1040A diode array detector (DAD) and an octadecyl silica (ODS) column using tetrahydrofuran/water $(4: 1 \mathrm{v} / \mathrm{v})$ and a DAD. Ionic chloride and sulfate levels were measured by dissolving the polymers in room temperature toluene and extracting with deionized water. Then, the aqueous extract was analyzed by ion chromatography (IC) using the Dionex model 4000 liquid chromatograph.

To determine structural composition, nuclear magnetic resonance (NMR) spectral analysis was performed using a General Electric GN300 NMR spectrometer. Proton NMR was used to quantitate the relative amount of hydrogen as CTBN, and carbon-13 NMR was used to measure nitrile content. These methods are capable of distinguishing incoming lots of CTBN that have a polybutadiene contaminant that is insoluble in the polymer matrix. The relative standard deviation was $3.9 \%$ for the proton NMR method and $8.3 \%$ for the carbon-13 NMR method. Presently, there is no method (other than carbon-13 NMR) for quantitating nitrile content. These methods are capable of distinguishing incoming lots of CTBN that have a polybutadiene contaminant that is insoluble in the polymer matrix. 


\section{DISCUSSION}

SCOPE AND PURPOSE

The project objective is to develop methods for analyzing high performance polymers. The specific objective of this report is to develop methods to analyze CTBN and the CTBN-epoxy adduct BKC 20102 produced in the polymer facility at Allied-Signal Inc., Kansas City Division (KCD).

PRIOR WORK

A CTBN-modified epoxy has been used at KCD since 1977,1 when it was shown that its thermal and electrical properties were equivalent to an unmodified system. The modified epoxy is tougher and only crazes when the unmodified epoxy cracks under high stress or impact loading.

ACTIVITY

\section{Ge1 Permeation Chromatography}

Ge1 permeation chromatography (GPC) is a liquid chromatographic method for measuring the molecular size of polymers. The sample is dissolved in room temperature tetrahydrofuran (THF) and is separated on a three-column set. The columns are packed with a porous poly(styrene/divinylbenzene). Small molecules fit easily into the pores and are retained on the column. Larger polymers do not fit into the pores and are not retained. Therefore, the highest molecular weight fractions are eluted first, and the lowest last. The data are used to calculate weight average, 
number average, and $\mathrm{Z}$-average molecular weights. ${ }^{2}, 3$ A GPC chromatogram of CTBN (Hycar $1300 \mathrm{X} 8$ ) is shown in Figure 1. A peak appears at about $37 \mathrm{~min}$, caused by the CTBN. The integral of this peak is shown in the lower part of Figure 1, together with a plot of the cumulative percent of material detected as a function of the logarithm of the molecular weight. These data are used to calculate the molecular weights. When CTBN is reacted with Epon 828 , the adduct has an increased molecular weight and produces a different chromatogram (Figure 2). This adduct has a higher average molecular weight as evidenced by the fact that the peak elutes sooner $(24 \mathrm{~min})$ than the CTBN. Data for different lots of CTBN are presented in Table 1. A number of physical properties of a polymer depend on its molecular weight and molecular weight distribution, or dispersity. Therefore, the GPC data are useful in establishing a basis to compare future lots of CTBN and adduct.

\section{High Performance Liquid Chromatography}

CTBN and CTB (Hycar $2000 \times 162$ ) were dissolved in 80 -percent THF and analyzed by high performance liquid chromatography (HPLC). They were separated on an ODS column and detected using a diode array detector (DAD) which can monitor up to six ultraviolet (UV) wavelengths simultaneously. As shown in Figure 3, CTB produces one major peak when the DAD monitors $253 \mathrm{~nm}$. The minor peak at 4 min becomes a major peak, though, when the DAD monitors $220 \mathrm{~nm}$. Thus, components of CTB have different molar absorptivities at specific wavelengths.

Typically, higher molecular weight polymers have a stronger absorbance at lower wavelengths and may be disproportionally represented in chromatograms such as the one in Figure 4. Likewise, СTBN has multiple components that can be identified when the DAD is set at $220 \mathrm{~nm}$, as shown in Figure 5. The HPLC data can be used to characterize incoming lots of CTBN. 


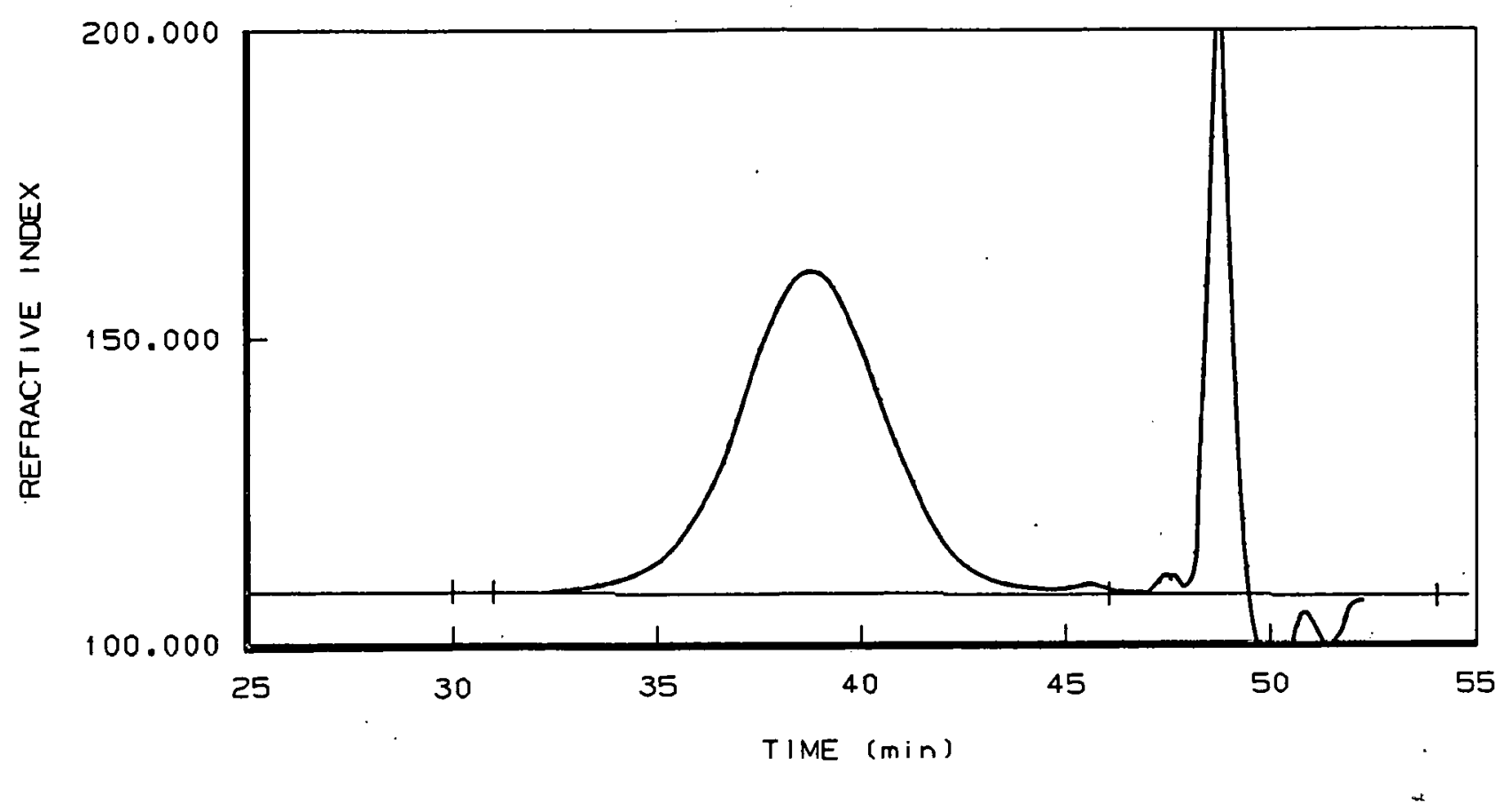

a. CHROMATOGRAM

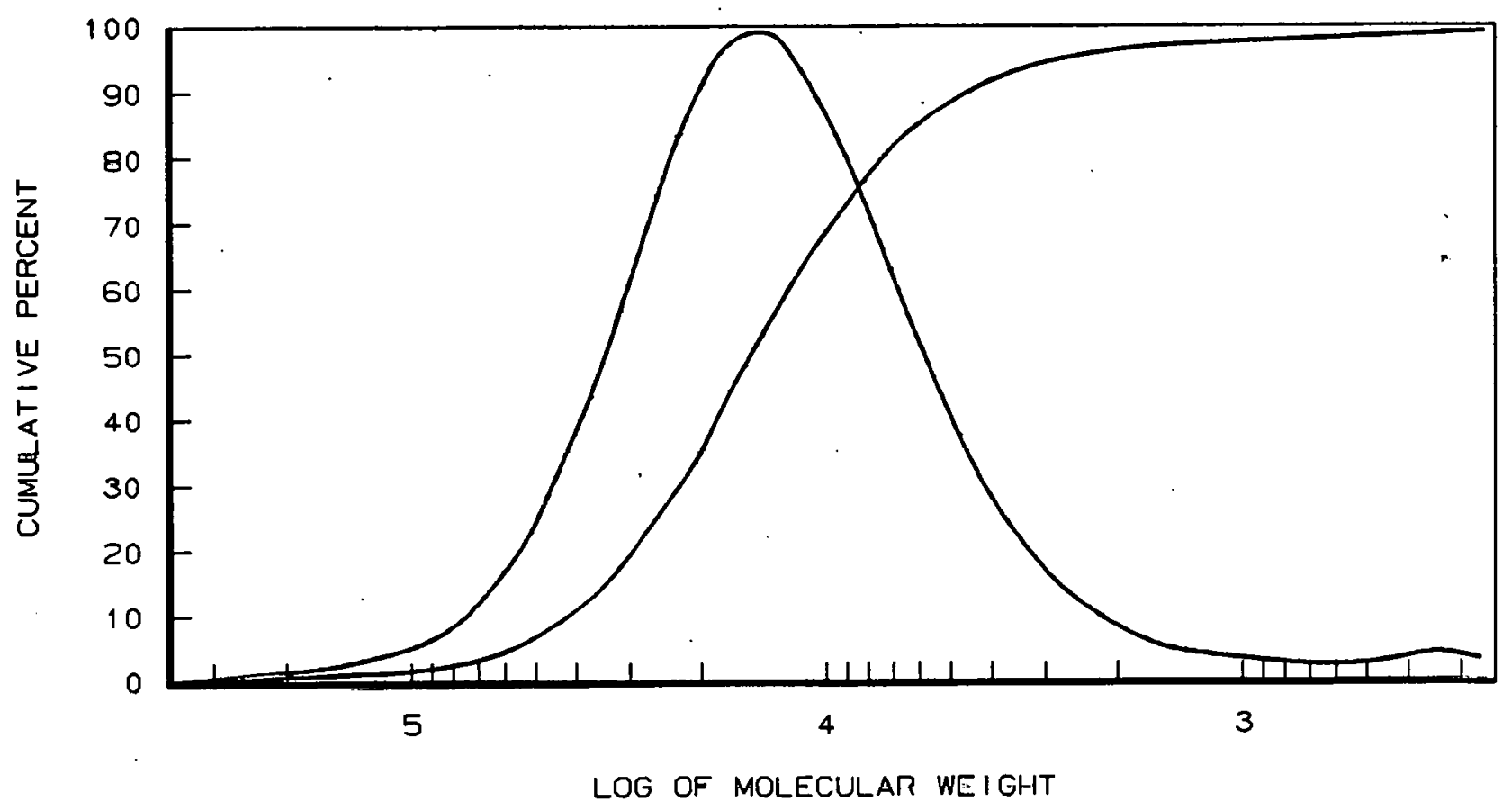

b. MOLECULAR WEIGHT

Figure 1. GPC of CTBN $1300 \times 8$ 


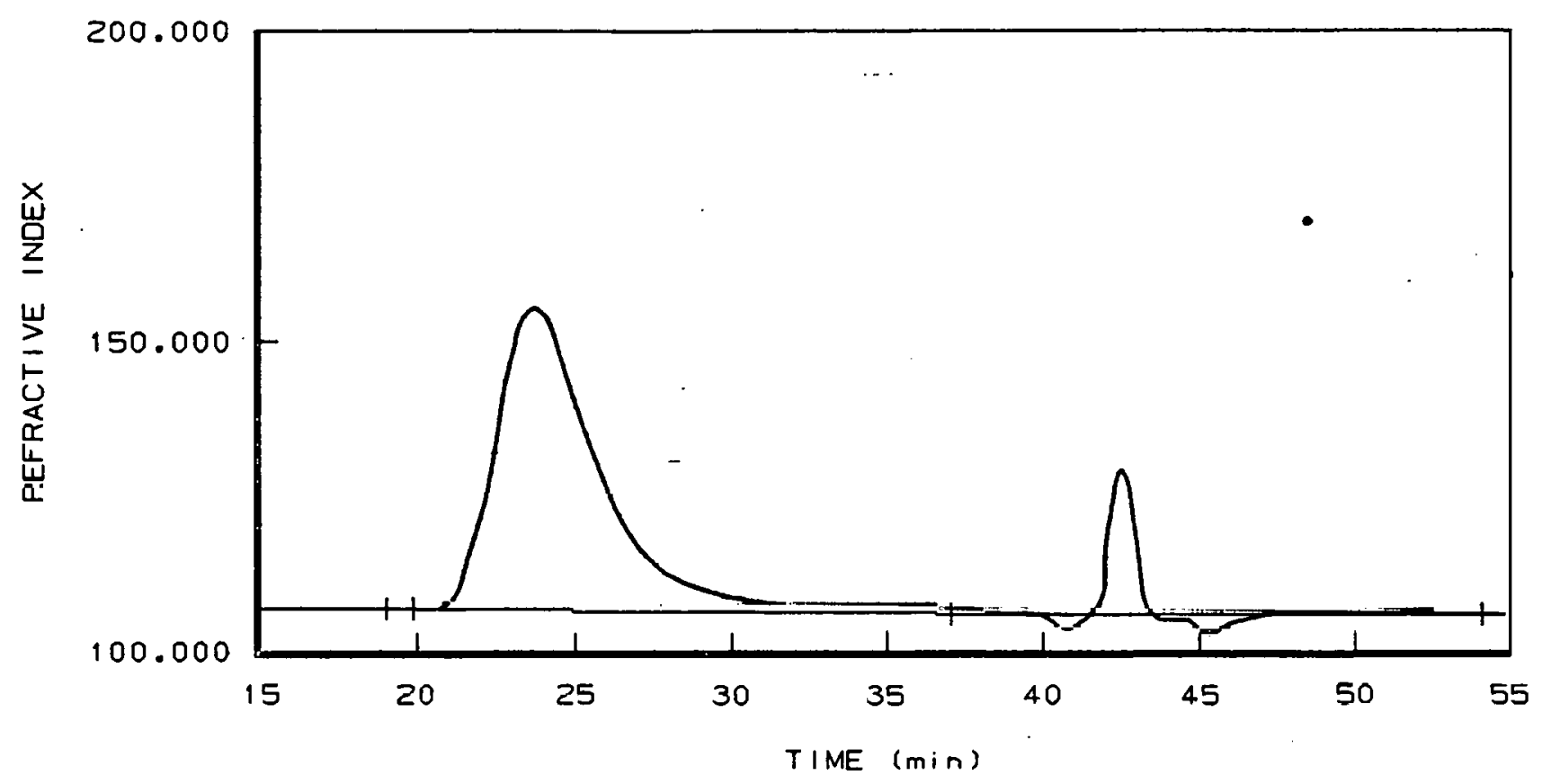

a. CHROMATOGRAM

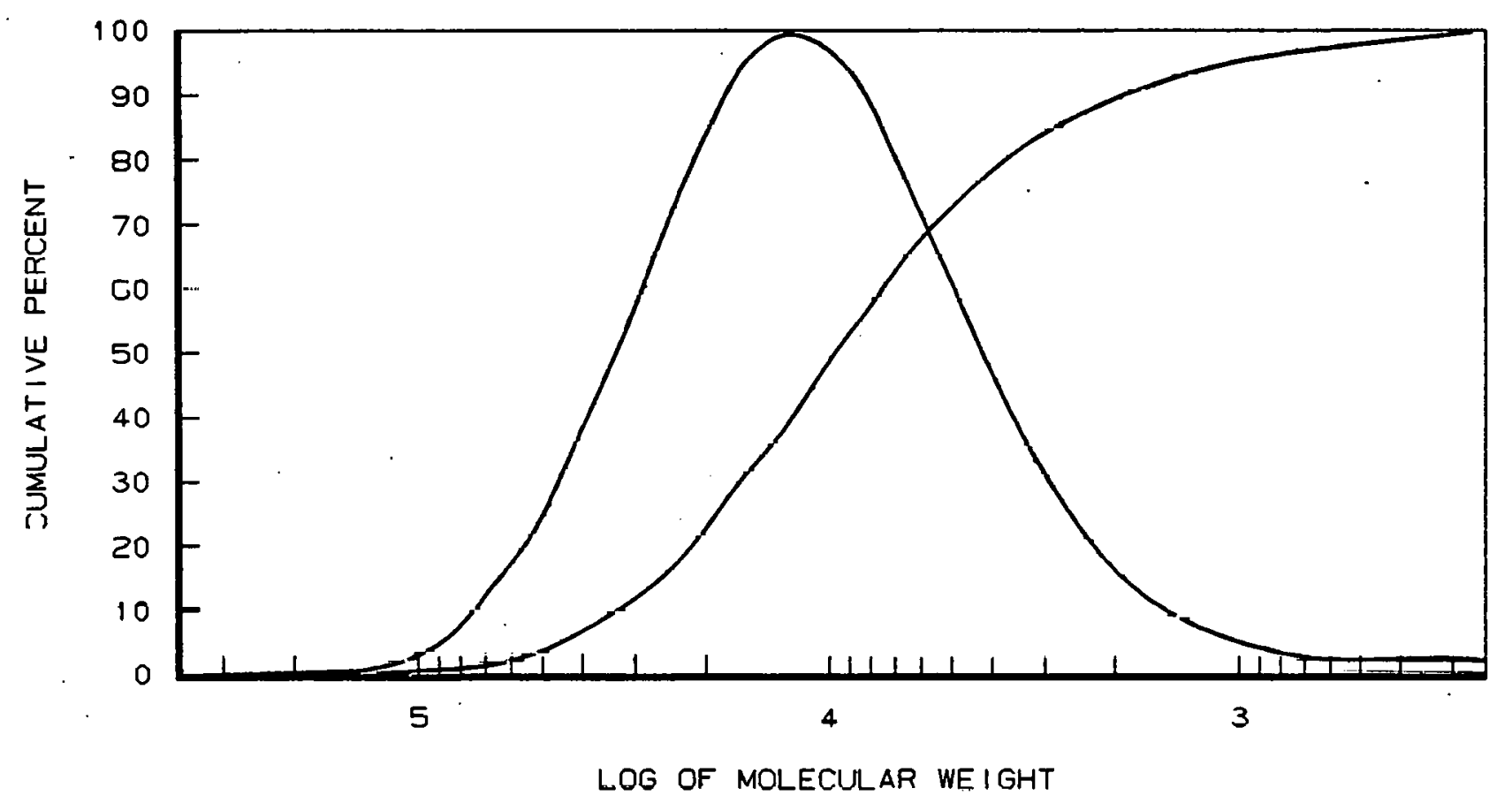

b. MOLECULAR WEIGHT

Figure 2. GPC of Epon 828-CTBN Adduct 
Table 1. GPC Data on CTBN

\begin{tabular}{llll}
\hline $\begin{array}{l}\text { Lot } \\
\text { Number }\end{array}$ & $\begin{array}{l}\text { Weight Average } \\
\text { Molecular Weight }\end{array}$ & $\begin{array}{l}\text { Number Average } \\
\text { Molecular Weight }\end{array}$ & Polydispersity \\
\hline 361212 & 5175 & 2176 & 2.38 \\
360808 & 5195 & 2110 & 2.46 \\
370403 & 5242 & 2110 & 2.48 \\
\hline
\end{tabular}

Ion Chromatography

To determine ionizable chloride, ion chromatography (IC) was used. The samples were dissolved in toluene and extracted with water. Ionic chloride and sulfate go into the aqueous phase and can be quantitated using IC methods. Values obtained for different lots of epoxy and adduct are given in Table 2 .

\section{Nuclear Magnetic Resonance}

Nuclear magnetic resonance (NMR) can be used to confirm the structural identity of CTBN and its adduct with Epon 828; NMR can also be used for quantitative analysis. The proton spectrum of CTBN is shown in Figure 6, where peak assignments are in accordance with the following structure:

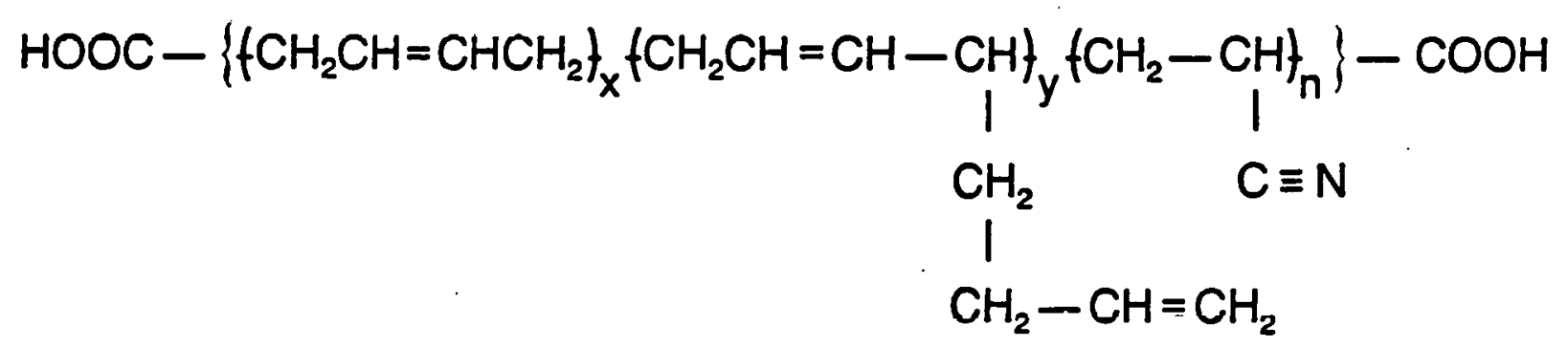

The alkyl groups $\left(\mathrm{CH}_{2}\right.$ and $\left.\mathrm{CH}\right)$ produce the peaks from 1.3 to $2.6 \mathrm{ppm}$, and the alkene groups $(-\mathrm{CH}=\mathrm{CH}-)$ produce the peaks from 4.9 to $5.2 \mathrm{ppm}$. The proton spectrum of CTB is quite similar, as shown in Figure 7 . Both are quite distinct from the proton NMR 


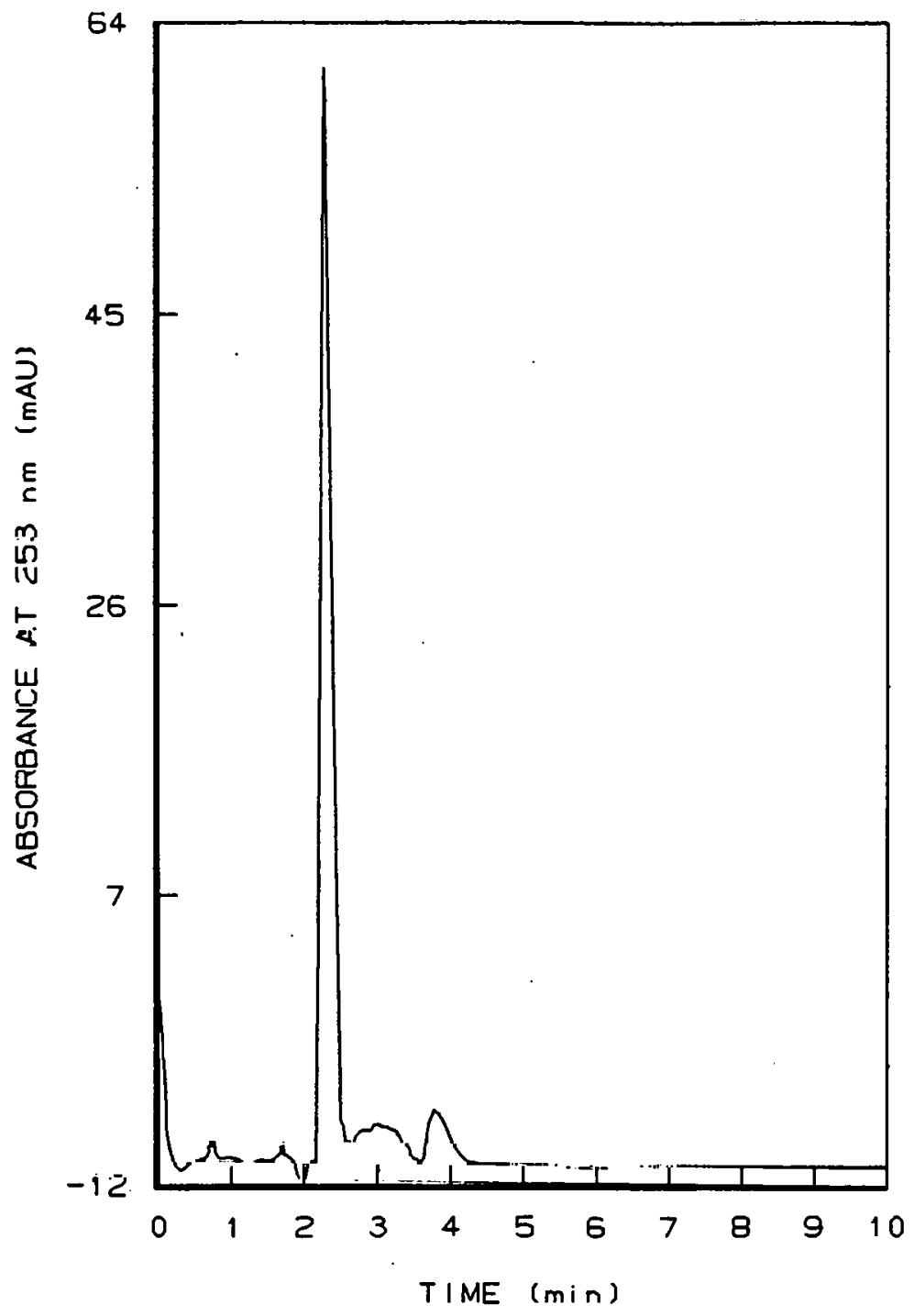

F1gure 3. HPLC of CTB=-Absorbance at $253 \mathrm{~nm}$

spectrum of Epon 828, which is primarily the diglycidyl ether of bisphenol. A (DGEBA):<smiles>CC(C)(c1ccc(OCC2CO2)cc1)c1ccc(OCC2CO2)cc1</smiles> 


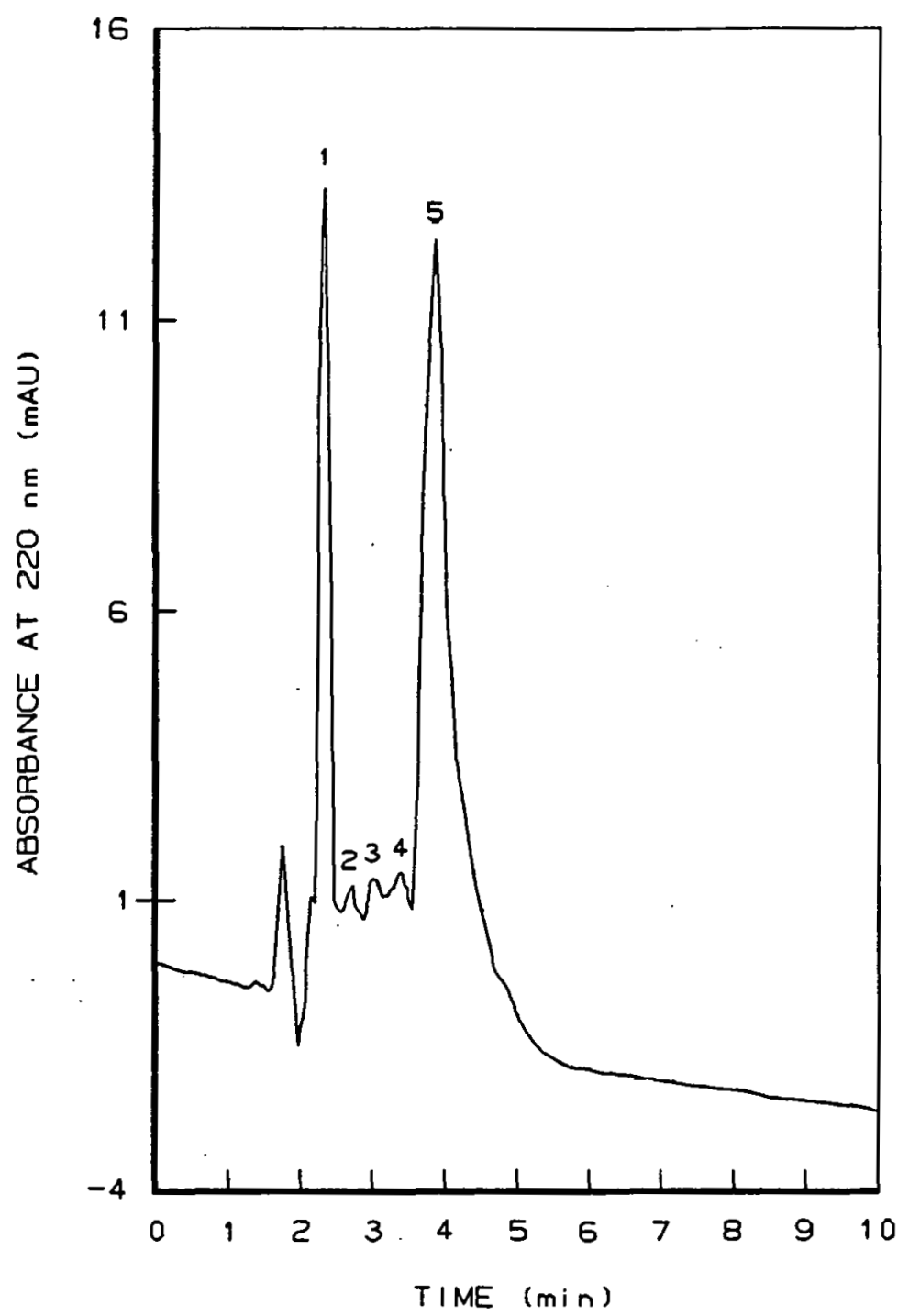

Figure 4. HPLC of CTB--Absorbance at $220 \mathrm{~nm}$

Its spectrum is also shown in Figure 7. The phenyl protons. produce the peaks near $7 \mathrm{ppm}$. The glycidyl ether protons produce the five sets of peaks from 2.6 to $4.2 \mathrm{ppm}$. The dimethyl protons produce the peak at $1.6 \mathrm{ppm}$. The CTBN-Epon 828 adduct produces a proton spectrum that contains peaks from each component, as shown in Figure 8. The relative size of the CTBN alkyl protons can be used to quantitate the amount of CTBN in the adduct. The results of the analysis of eight different adducts are shown in Table 3 . 


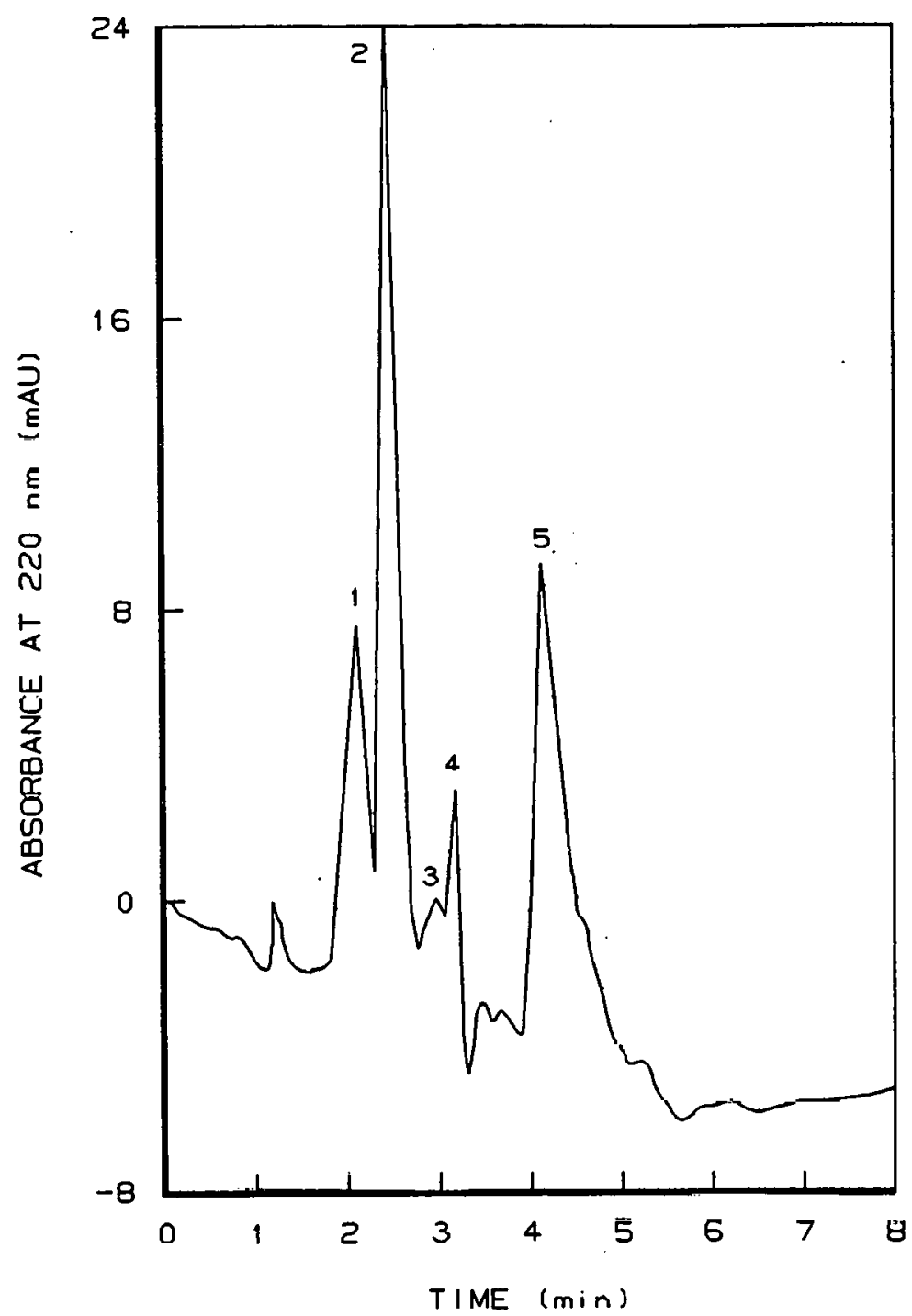

Figure 5. HPLC of CTBN $1300 \times 8$

The relative standard deviation of five replicates is $3.9 \%$. Sample 14 exhibitcd a phace separation, indicating the presence of an insoluble contaminant. The abnormal percent of alkyl protons observed in this sample confirms its unusual composition and the ability of proton NMR to screen samples for quality assurance. 
Table 2. Ions in Epoxy and Adduct

\begin{tabular}{lll}
\hline $\begin{array}{l}\text { Lot } \\
\text { Number }\end{array}$ & $\begin{array}{l}\mathrm{Cl}^{-} \\
(\mathrm{ppm})\end{array}$ & $\begin{array}{l}\mathrm{SO}_{4}^{2-} \\
(\mathrm{ppm})\end{array}$ \\
\hline Epoxy & & \\
\hline 860506 & 72 & 2.9 \\
811208 & 16 & 0.74 \\
861029 & 65 & 1.2 \\
\hline CTBN & & \\
\hline 340623 & 153 & 11 \\
360808 & 165 & 16 \\
361212 & 144 & 25 \\
\hline
\end{tabular}

To measure the nitrile content, carbon, hydrogen, and nitrogen analyses were performed. Unfortunately, only total nitrogen can be determined, so trapped nitrogen gas can cause appreciable interferences: To directly observe the nitrile group, carbon-13 NMR was used. As shown in Figure 9, the methylene and methine carbons in CTBN produce a set of peaks from 22 to $45 \mathrm{ppm}$. There are so many peaks in this region because the chemical environments of the methylene and methine carbons are slightly different. A methylene carbon adjacent to a $-\mathrm{COOH}$ would produce a different peak from a methylene several carbons away from a $-\mathrm{COOH}$. Similarly, a methylene located in a block of $-\mathrm{CH}_{2}-\mathrm{CH}=\mathrm{CH}-\mathrm{CH}_{2}-$ will produce a different peak from a methylene in a $-\mathrm{CH}_{2}-\mathrm{CH}=\mathrm{CH}-\mathrm{CH}_{2}$ adjacent to an acrylonitrile group. Likewise, a methylene located in a branch or an acrylonitrile (see below)

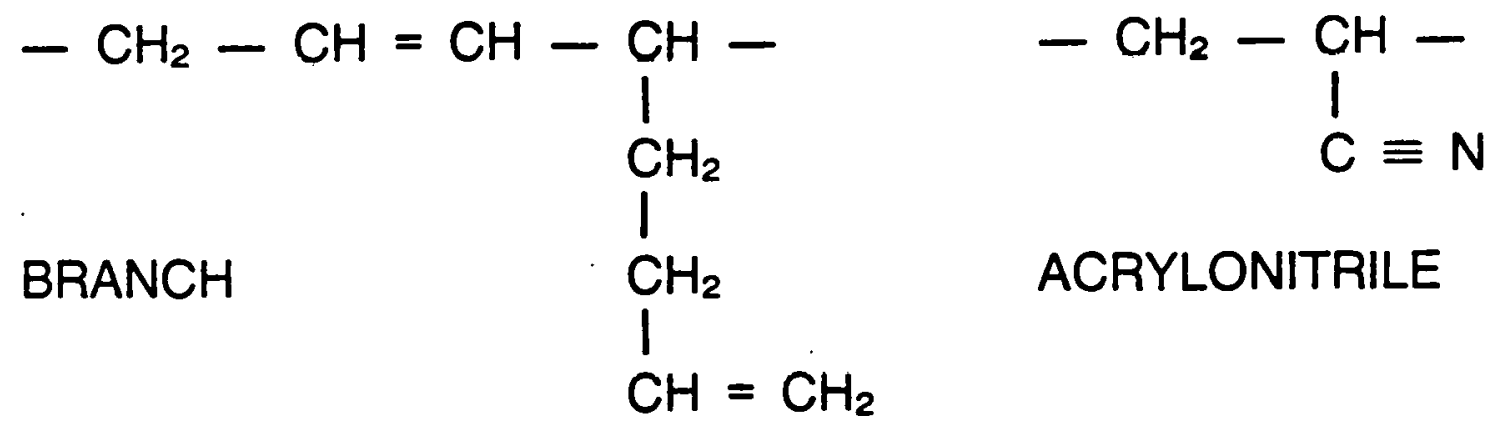




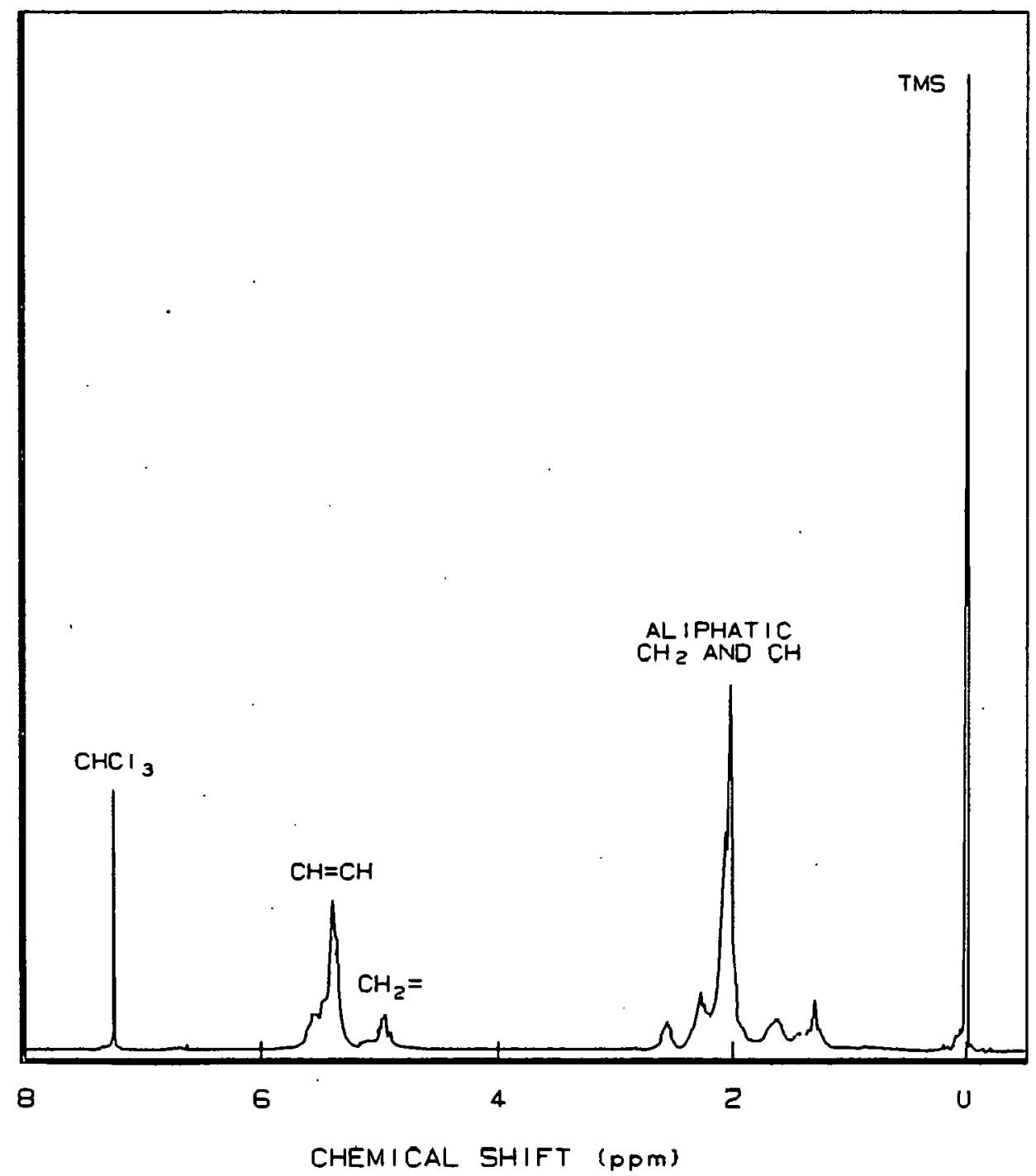

Figure 6. Proton NMR of CTBN 1300 X8

will produce a different peak than a methylene in a straight chain (that io, $-\mathrm{CH}_{2}-\mathrm{CH}=\mathrm{CH}-\mathrm{CH}_{2}$ ). For the same reasnn, there are several peaks produced by the $-\mathrm{CH} \equiv \mathrm{CH}$-carbons lucaled in slightly different environments. The nitrile and $-\mathrm{COOH}$ groups, though, produce distinct peaks (as labeled in Figure 9) whose areas are easily integrated, enabling quantitative analysis. Likewise, the $-\mathrm{CH}=$ groups in butadiene branches produce a distinct peak.

The carbon-13 spectrum of CTB is almost the same as that for CTBN, except that there is no nitrile peak (Figure 10). Thus, 


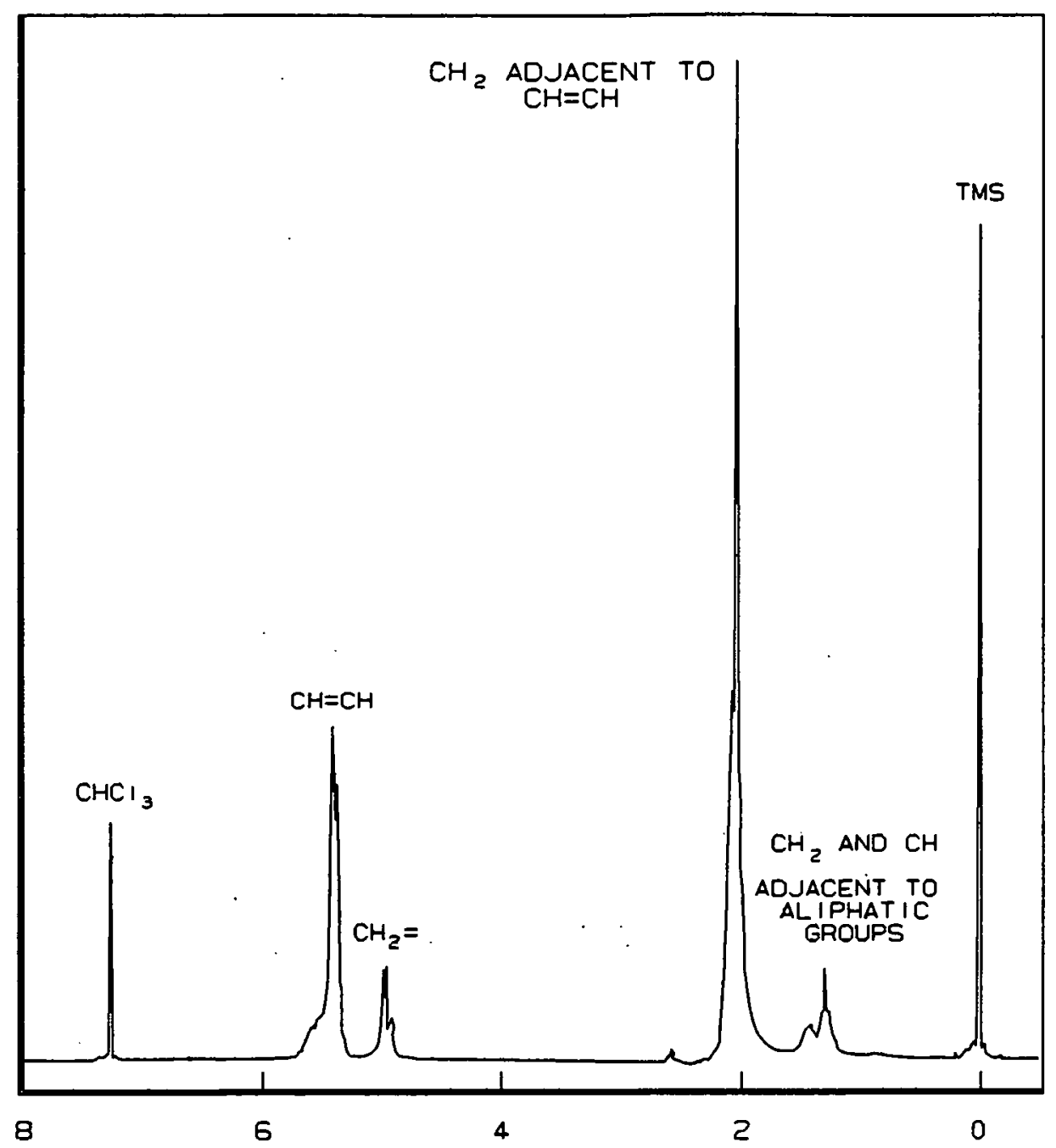

CHEMICAL SHIFT (ppm)

Figure 7. Proton NMR of CTB in $\mathrm{CDCl}_{3}$

when analyzing CTBN/Epon 828 adducts, the relative size of the nitrile peak is directly related to the amount of CTBN in the adduct.

The carbon-13 spectrum of the adduct displays the peaks caused by DGEBA prominantly (Figure 11). To ensure production of an acceptable adduct, it may be useful to analyze the raw material, that is, the CTBN. To do this, standards containing increasing amounts of CTB mixed with CTBN were prepared by Materlals 


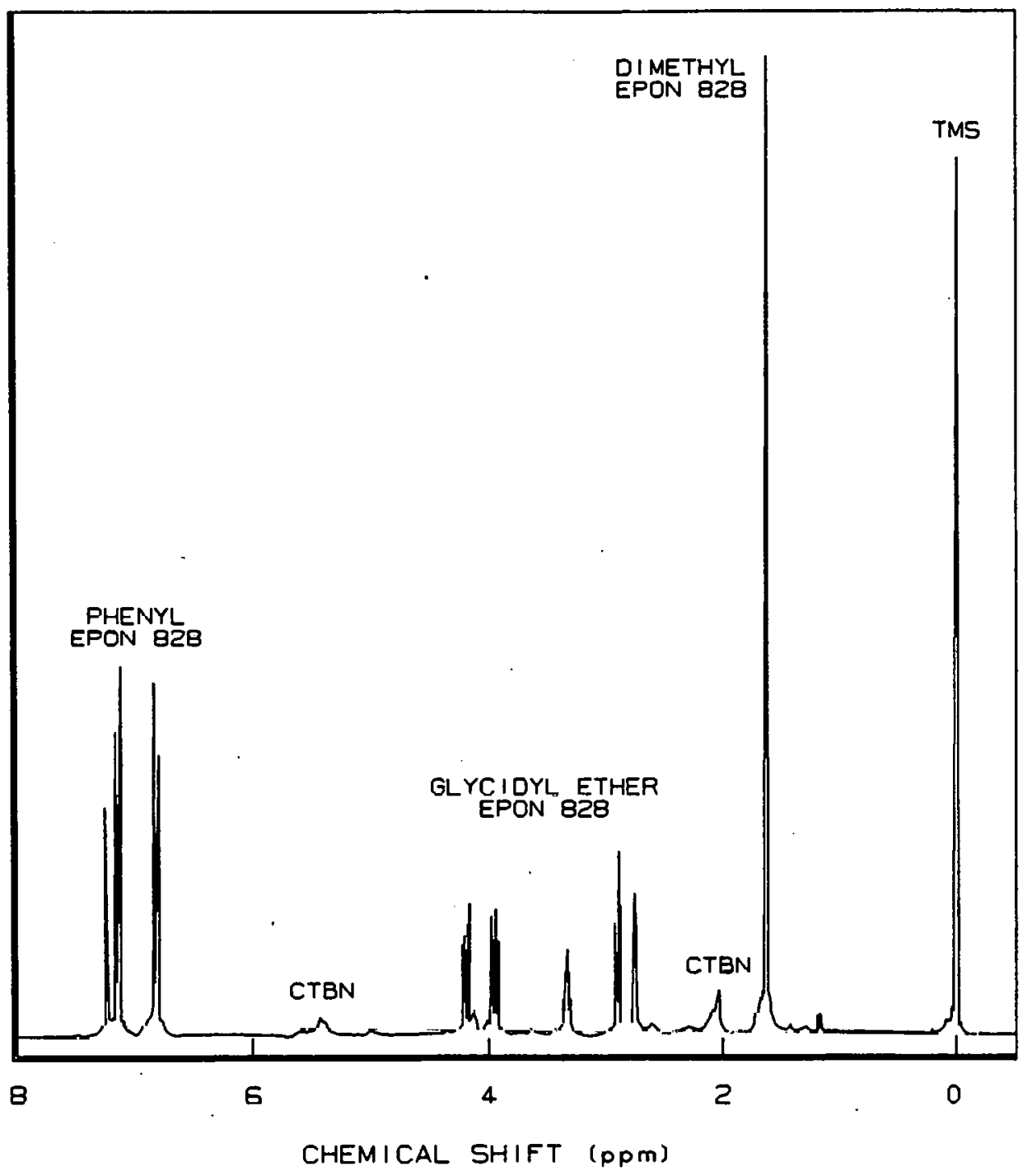

Figure 8. Proton NMR of Epon 828-CTBN Adduct in $\mathrm{CDCl}_{3}$

Engineering. These standards were analyzed by carbon-13 NMK; the results are summarized in Table 4 . The relative standard deviation of five replicate measurements was $8.3 \%$. These standards will be useful in any analyses of future lots of CTBN.

The methods used for the proton and carbon-13 NMR analyses were written and are summarized in the appendix of this report. They are available for use if needed. 
Table 3. Proton NMR Analysis Showing Hydrogen in Samples of CTBN/Epon 828

\begin{tabular}{ll}
\hline $\begin{array}{l}\text { Sample } \\
\text { Number }\end{array}$ & $\begin{array}{c}\text { Hydrogen } \\
\text { (percent) }\end{array}$ \\
\hline 8 & 13.7 \\
9 & 13.2 \\
10 & 13.4 \\
11 & 12.7 \\
12 & 12.5 \\
13 & 13.2 \\
14 & 18.5 \\
15 & 13.5 \\
\hline
\end{tabular}

\section{ACCOMPLISHMENTS}

Two polymers, CTB and CTBN, and the adduct of CTBN with epoxy have been analyzed by several methods. The molecular weight distribution was measured by GPC. HPLC was used to separate the major components from minor constituents. Ion chromatography was used to determine ionic chloride and sulfate. Proton NMR was used to quantitate the percent of hydrogens in the epoxy-CTBN: adduct caused by the CTBN. Carbon-13 NMR was used to analyze CTBN and CTB for nitrile content. The relative standard deviation was $3.9 \%$ for the procon NMR method and $8.3 \%$ for the carbon-13 NMR method. Both NMR methods provide information not available by any other technique. 


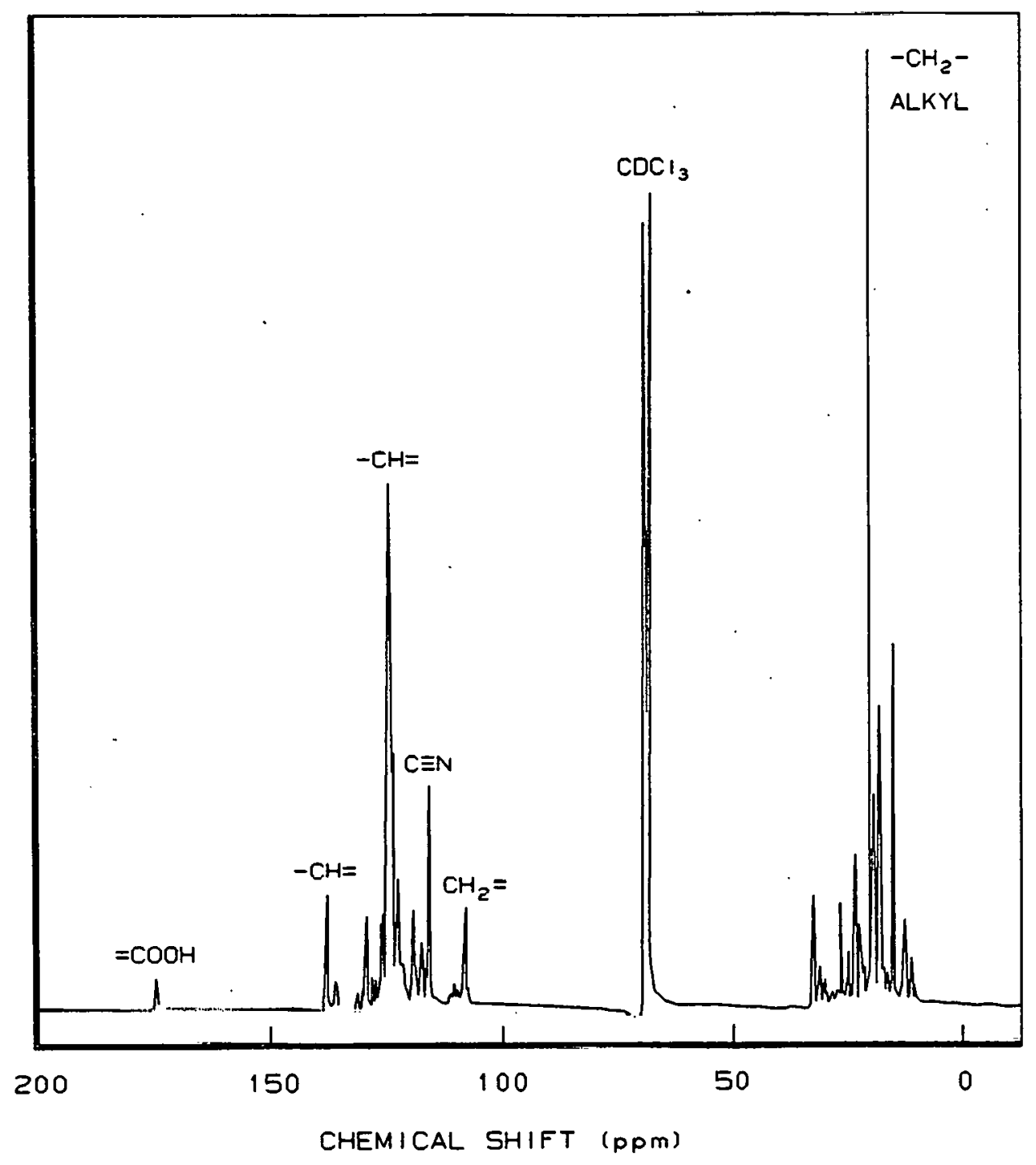

Figure 9. Carbon-13 NMR of CTBN $1300 \times 8$ in $\mathrm{CDCl}_{3}$ 


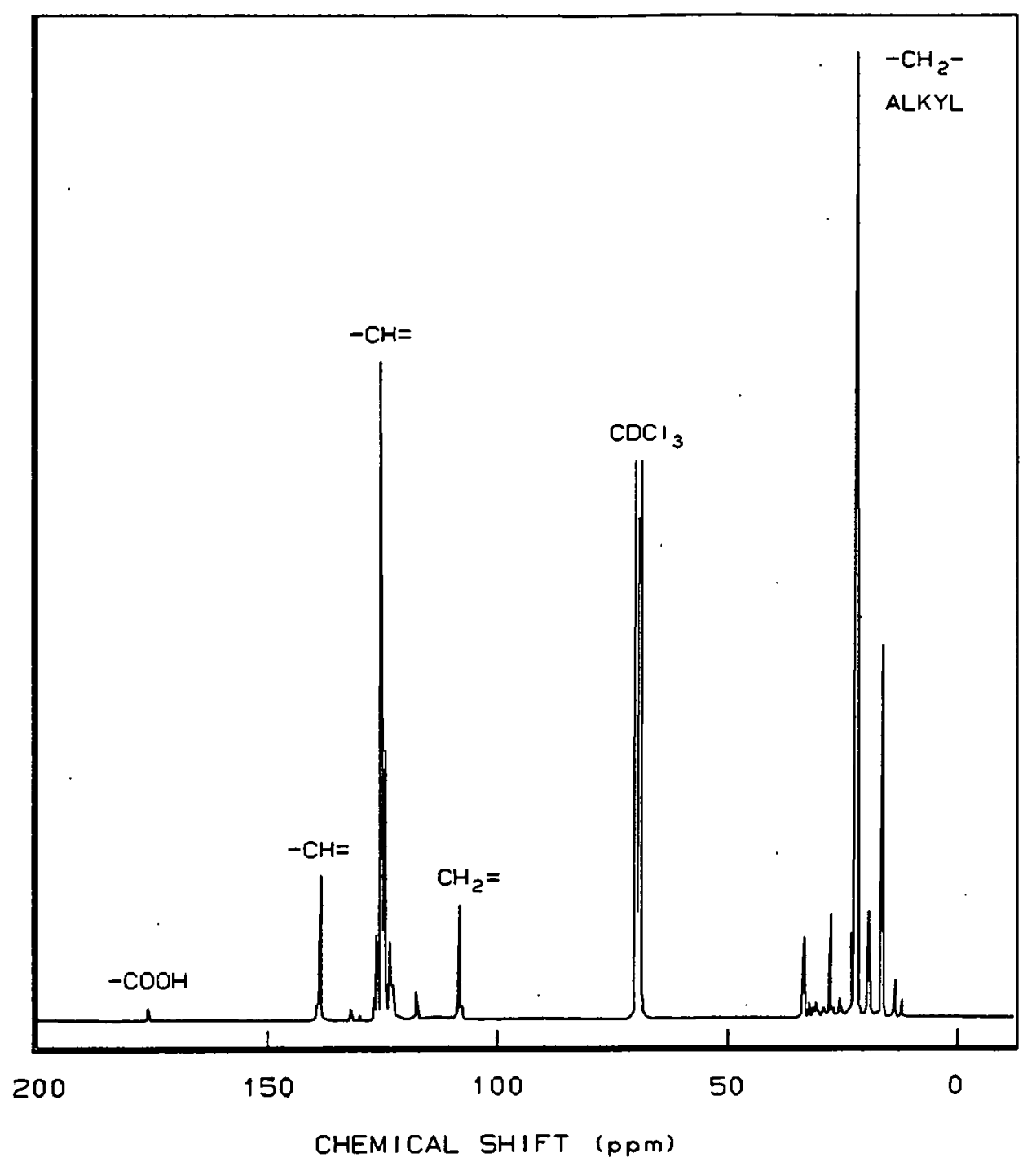

Figure 10. Carbon-13 NMR of CTB in $\mathrm{CDCl}_{3}$ 


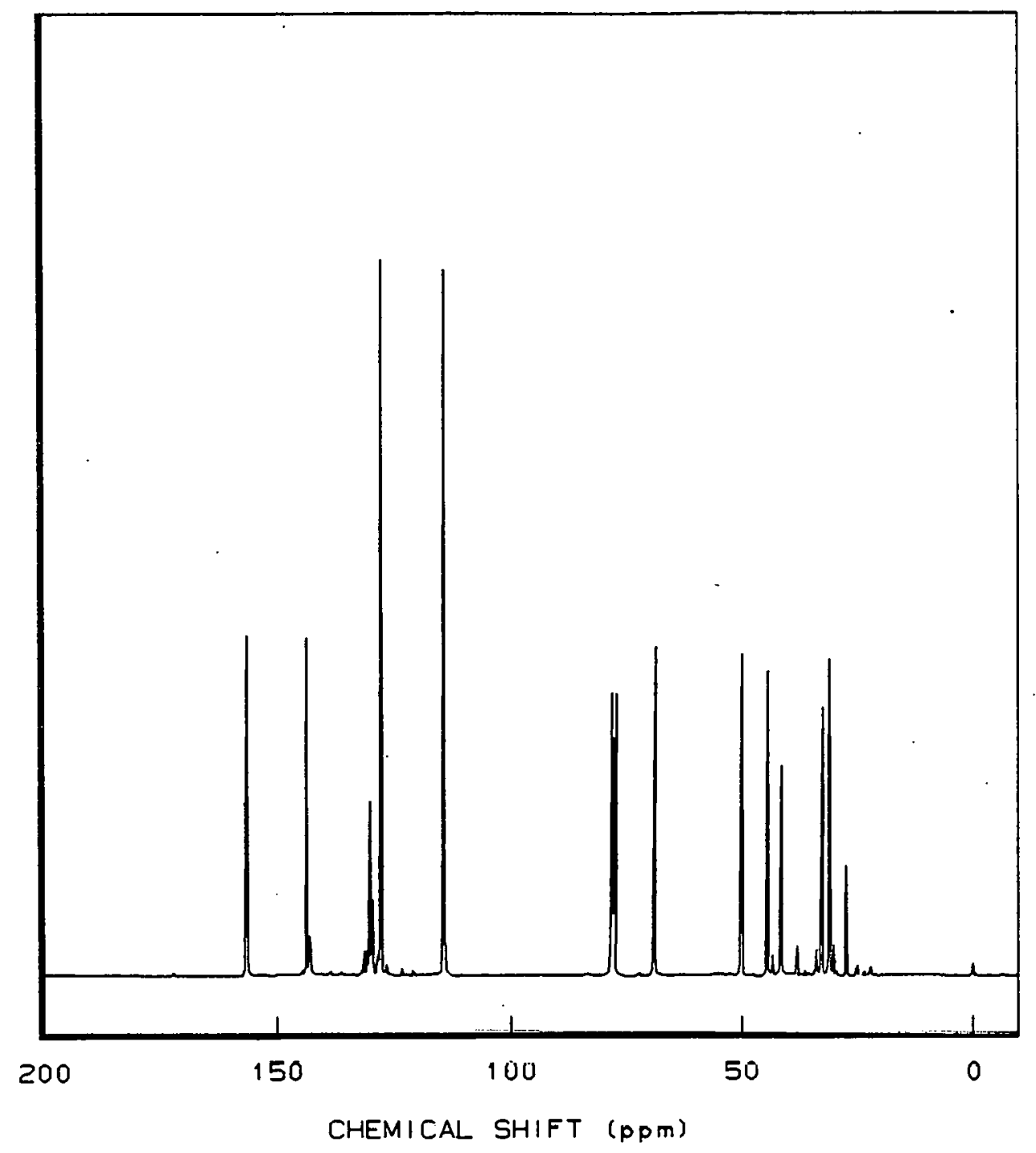

Figure 11. Carbon-13 NMR of Epon 828-CTBN Adduct in $\mathrm{CDCl}_{3}$ 
Table 4. Carbon-13 NMR Analysis Showing Carbon in Samples of CTB and CTBN

\begin{tabular}{llll}
\hline \multirow{2}{*}{$\begin{array}{l}\text { Sample } \\
\text { Number }\end{array}$} & \multicolumn{2}{c}{ Carbon Content } & \\
\cline { 2 - 4 } & $\mathrm{C} \equiv \mathrm{N}$ & $\mathrm{COOH}$ & $\mathrm{CH}_{2}=\mathrm{CH}-$ \\
\hline CTB & 0.0 & 0.68 & 18.4 \\
CTBN & 4.29 & 0.60 & 15.8 \\
4 & 4.21 & 0.61 & 16.0 \\
5 & 4.03 & 0.59 & 16.1 \\
6 & 3.70 & 0.65 & 16.2 \\
7 & 3.60 & 0.63 & 16.4 \\
\hline
\end{tabular}




\section{REFERENCES}

1J. M. Walker, W. E. Richardson, and C. H. Smith, "CTBN-Modified Epoxy Encapsulant". Modern Plastics, Volume 54, Number 68, 1977.

${ }^{2}$ B. Vollmert, Polymer Chemistry. New York: Springer-Verlag, 1973 , pp. $426-427$.

${ }^{3}$ W. W. Yan, J. J. Kirkland, and D. D. Bly, Modern Size-Exclusion Liquid Chromatography. New York: John Wiley and Sons, 1979. 
Appendix A

EXPERIMENTAL METHODS

NMR. All spectra were recorded using a GN300 spectrometer from General Electric (Fremont, CA). For proton NMR, the spectrometer frequency was $300.100 \mathrm{MHz}$. A 90-degree pulse width (10 microseconds) and an 8-second pulse delay were used. A sweep width of $\pm 2000 \mathrm{~Hz}$ was used. For carbon-13 NMR, the spectrometer frequency was $75.12345 \mathrm{MHz}$. A 30-degree pulse width and a 0.5-second pulse delay were used. Broad-band proton decoupling was employed. The sweep width was $\pm 10,000 \mathrm{~Hz}$.

Ion Chromatography. Chromatograms of aqueous extracts of the polymer dissolved in toluene were obtained using a Dionex (Sunnyvale, CA) model 4000 ion chromatograph equipped with an anion micromembrane suppressor (AMMS), a conductivity detector, and an AS4A separator column. The eluent was $3 \mathrm{mM} \mathrm{NaHCO}_{3}$ plus $2.4 \mathrm{mM} \mathrm{Na}{ }_{2} \mathrm{CO}_{3}$. 